\title{
Hubungan Akne Vulgaris Dengan Gejala Ansietas Pada Mahasiswa Fakultas Kedokteran Universitas Muhammadiyah Sumatera Utara
}

\author{
Arisa Atika Meliala ${ }^{1}$, Riri Arisanty Safirin Lubis ${ }^{2}$ \\ ${ }^{1}$ Fakultas Kedokteran, Universitas Muhammadiyah Sumatera Utara \\ ${ }^{2}$ Departemen IImu Kesehatan Kulit dan Kelamin, Fakultas Kedokteran, Universitas Muhammadiyah Sumatera \\ Utara \\ email: Arisaam09@gmail.com
}

\begin{abstract}
Abstrak
Akne vulgaris (AV) adalah penyakit kulit akibat inflamasi kronis folikel pilosebasea yang ditandai dengan adanya komedo, papul, pustul, nodus, dan kista. Akne sering ditemukan pada wajah, berdampak besar pada penampilan visual seseorang, sehingga dapat mempengaruhi fungsi emosional, sosial, psikologis serta kualitas hidup penderitanya. Beberapa penelitian menunjukkan bahwa AV memiliki dampak negatif pada kepercayaan diri pasien. Kepercayaan diri yang rendah berhubungan dengan kecemasan dan depresi. Mengetahui hubungan AV dengan gejala ansietas pada mahasiswa Fakultas Kedokteran Universitas Muhammadiyah Sumatera Utara. Jenis penelitian yang dilaksanakan bersifat cross sectional. Subjek pada penelitian ini adalah mahasiswa Fakultas Kedokteran Universitas Muhammadiyah Sumatera Utara. Hasil penelitian ini menggunakan uji ChiSquare, dan didapatkan nilai $p$-valuae $=0,020$. Terdapat hubungan AV dengan gejala ansietas pada mahasiswa Fakultas Kedokteran Universitas Muhammadiyah Sumatera Utara.
\end{abstract}

Kata Kunci : Akne Vulgaris, Ansietas

(c) EY This work is licensed under a Creative Commons Attribution 3.0 License.

\section{PENDAHULUAN}

Akne atau jerawat adalah penyakit kulit akibat peradangan kronis folikel pilosebasea yang ditandai dengan adanya komedo, papul, pustul, nodus, dan kista pada daerah yang memiliki kelenjar palit atau sebasea seperti wajah, punggung dan dada. ${ }^{1}$ Akne vulgaris adalah kondisi yang sangat umum yang mempengaruhi hingga $93 \%$ remaja. Penyakit ini, meskipun jarang, bertahan hingga usia dewasa. $^{3}$ Akne sering ditemukan pada daerah wajah, yang memiliki dampak besar pada penampilan visual dan dapat mempengaruhi fungsi emosional, sosial, psikologis serta kualitas hidup pasien. ${ }^{4}$ Penyakit ini bukan merupakan penyakit yang berbahaya namun mempunyai dampak yang besar bagi para penderitanya baik secara fisik maupun psikologik, beberapa kasus bahkan dapat menimbulkan kecemasan dan depresi. Wajah yang berjerawat akan berpengaruh pula pada perkembangan psikososial termasuk kepercayaan diri. ${ }^{5}$ Akne vulgaris dapat memiliki dampak besar pada harga diri dan citra diri. Pengembangan harga diri dan identitas pribadi sangat penting pada orang dewasa muda. ${ }^{6}$ Penyakit kulit yang berpotensi menyebabkan menurunnya kepercayaan diri, salah satuna akne vulgaris, dapat berdampak negatif pada kematangan psikososial dan seksual. Kepercayaan diri yang rendah dapat dikaitkan dengan kecemasan dan depresi. $^{6}$ 
Gangguan kecemasan atau ansietas adalah salah satu gangguan mental yang paling umum di Amerika Serikat, dan dapat berdampak negatif terhadap kualitas hidup pasien dan mengganggu kegiatan penting dalam kehidupan sehari-hari. ${ }^{7}$ Ansietas merupakan keadaan emosi yang tidak menyenangkan berupa rasa takut yang subjektif, rasa tidak nyaman pada tubuh, dan gejala fisik. $^{8}$ Beberapa penelitian menunjukkan AV memiliki dampak negatif pada kepercayaan diri pasien. Kepercayaan diri yang rendah berhubungan dengan kecemasan dan depresi. Suatu penelitian menemukan bahwa semakin muda usia siswa ketika timbul jerawat, semakin besar stres dan kecemasan yang akan dialami seseorang. Mereka menemukan bahwa $70 \%$ pasien berusia 30 hingga 39 tahun paling terganggu oleh penampilan jerawat dari 60 subjek yang diperiksa. ${ }^{6}$ Penelitian ini bertujuan untuk mengetahui hubungan AV dengan gejala ansietas pada mahasiswa Fakultas Kedokteran Universitas Muhammadiyah Sumatera Utara.

\section{METODE PENELITIAN}

Jenis penelitian yang akan dilaksanakan bersifat cross sectional, yaitu dimana pengambilan data hanya diambil satu kali pengambilan untuk menganalisis hubungan AV dengan gejala ansietas pada mahasiswa Fakultas Kedokteran Universitas Muhammadiyah Sumatera Utara.

Penelitian ini dilakukan di Fakultas Kedokteran Universitas Muhammadiyah Sumatera Utara. Proses penelitian ini dilakukan pada bulan Oktober - Januari 2020. Populasi pada penelitian ini dilakukan terhadap mahasiswa Fakultas Kedokteran Universitas Muhammadiyah Sumatera Utara yang berjumlah 65 orang. Data yang dikumpulkan peneliti terdiri atas data primer dan data sekunder. Data primer yang digunakan adalah kuesioner kecemasan, Hamilton Anxiety Rating Scale (HARS). Hamilton Anxiety Rating Scale (HARS) adalah kuesioner untuk menilai tingkat kecemasan yang terdiri dari 14 item pertanyaan. Data sekunder yang digunakan ialah derajat keparahan AV menurut Klasifikasi Pillsburry. Kemudian peneliti melakukan uji statistika dengan menggunakan uji chi-square.

\section{HASIL PENELITIAN}

Penelitian ini dilaksanakan di Fakultas Kedokteran Universitas Muhammadiyah Sumatera Utara. Penelitian ini dilakukan dari bulan Desember 2019 hingga Januari 2020.

Tabel 1. Distribusi data demografi sampel berdasarkan jenis kelamin dan usia

\begin{tabular}{llc}
\hline & $\mathbf{N}$ & $\%$ \\
\hline Jenis & & \\
Kelamin & & \\
Laki-laki & 27 & $41,5 \%$ \\
Perempuan & 38 & $58,5 \%$ \\
\hline \multicolumn{1}{c}{ Usia } & & \\
21 & 55 & $84,6 \%$ \\
22 & 10 & $15,4 \%$ \\
\hline
\end{tabular}

Berdasarkan tabel 1 terlihat bahwa frekuensi terbanyak untuk kelompok jenis kelamin adalah perempuan dengan jumlah 38 orang (58,5\%). Sampel penelitian ini di ambil dari populasi mahasiswa Fakultas Kedokteran Universitas Muhammadiyah Sumatera Utara, yang telah memenuhi kriteria inklusi. Sedangkan untuk kategori usia yang paling banyak adalah usia 21 tahun 55 orang $(84,6 \%)$. 
Tabel 2. Distribusi gambaran derajat Acne Vulgaris

\begin{tabular}{|c|c|c|}
\hline $\begin{array}{c}\text { Derajat Acne } \\
\text { Vulgaris }\end{array}$ & $\mathbf{N}$ & $\%$ \\
\hline Grade 1 & 37 & $56,9 \%$ \\
\hline Grade 2 & 16 & $24,6 \%$ \\
\hline Grade 3 & 8 & $12,3 \%$ \\
\hline Grade 4 & 4 & $6,2 \%$ \\
\hline Total & 65 & $100 \%$ \\
\hline
\end{tabular}

Berdasarkan tabel 2 bahwa mahasiwa yang paling banyak menderita AV adalah AV grade 1 berjumlah 37 orang (56,9\%).

Tabel 3. Distribusi gambaran gejala kecemasan

\begin{tabular}{lcc}
\hline \multicolumn{1}{c}{ Gejala Kecemasan } & $\mathbf{N}$ & $\%$ \\
\hline Tidak ada kecemasan & 13 & $20 \%$ \\
Kecemasan ringan & 19 & $29,2 \%$ \\
Kecemasan sedang & 7 & $10,8 \%$ \\
Kecemasan berat & 14 & $21,5 \%$ \\
Kecemasan berat sekali & 12 & $18,5 \%$ \\
\hline \multicolumn{1}{c}{ Total } & 65 & 100 \\
\hline
\end{tabular}

Berdasarkan tabel 3 bahwa mahasiswa yang paling banyak mengalami gejala kecemasan adalah kecemasan ringan berjumlah 19 orang $(29,2 \%)$.

Tabel 4. Hubungan Acne Vulgaris dengan Gejala kecemasan (ansietas)

\begin{tabular}{|c|c|c|c|c|c|c|c|c|c|c|c|c|c|c|}
\hline & & \multicolumn{12}{|c|}{ Tingkat Kecemasan } & \multirow{3}{*}{$\begin{array}{c}\text { P- } \\
\text { Value }\end{array}$} \\
\hline & & \multicolumn{2}{|c|}{$\begin{array}{l}\text { Tidak ada } \\
\text { kecemasan }\end{array}$} & \multicolumn{2}{|c|}{$\begin{array}{c}\text { Kecemasan } \\
\text { Ringan }\end{array}$} & \multicolumn{2}{|c|}{$\begin{array}{l}\text { Kecemasan } \\
\text { Sedang }\end{array}$} & \multicolumn{2}{|c|}{$\begin{array}{c}\text { Kecemasan } \\
\text { Berat }\end{array}$} & \multicolumn{2}{|c|}{$\begin{array}{c}\text { Kecemasan } \\
\text { Berat } \\
\text { Sekali }\end{array}$} & \multicolumn{2}{|c|}{ Jumlah } & \\
\hline & & F & $\%$ & F & $\%$ & $\mathrm{~F}$ & $\%$ & f & $\%$ & F & $\%$ & F & $\%$ & \\
\hline \multirow{5}{*}{$\begin{array}{c}\text { Acne } \\
\text { Vulgaris }\end{array}$} & Grade 1 & 11 & 16,9 & 11 & 16,9 & 5 & 7,7 & 8 & 12,3 & 2 & 3,1 & 37 & 56,9 & \multirow[t]{4}{*}{0,020} \\
\hline & Grade 2 & 0 & 0,0 & 7 & 10,8 & 2 & 3,1 & 2 & 3,1 & 5 & 7,7 & 16 & 24,6 & \\
\hline & Grade 3 & 2 & 3,1 & 1 & 1,5 & 0 & 0,0 & 3 & 4,6 & 2 & 3,1 & 8 & 12,3 & \\
\hline & Grade 4 & 0 & 0,0 & 0 & 0,0 & 0 & 0,0 & 1 & 1,5 & 3 & 4,6 & 4 & 6,2 & \\
\hline & Jumlah & 13 & 20,0 & 19 & 29,2 & 7 & 10,8 & 14 & 21,5 & 12 & 18,5 & 65 & 100,0 & \\
\hline
\end{tabular}

Data hasil uji chi-square pada table 4 menunjukan $p$-value 0,020 yang berarti terdapat hubungan AV dengan gejala Ansietas.

\section{DISKUSI}

Pada hasil penelitian, berdasarkan jenis kelamin menunjukkan bahwa penderita AV berjenis kelamin perempuan lebih banyak dengan jumlah 38 orang $(58,5 \%)$ dan laki-laki 27 orang $(41,5 \%)$. Hal ini sesuai dengan penelitian yang dilakukan oleh Sampelan, Pangamanan, and Kundre pada tahun 2017, yang menunjukkan bahwa jenis kelamin terbanyak dalam penelitian adalah perempuan dengan jumlah $(54,8 \%)$ dan laki-laki dengan jumlah $(45,2 \%) .{ }^{5}$ Sama dengan penelitian yang dilakukan sebelumnya oleh Manarisip (2015), dimana responden berjenis kelamin perempuan lebih tinggi dari pada reponden laki-laki. Karena jumlah mahasiswa perempuan yang memang lebih besar dari jumlah mahasiswa lakilaki. ${ }^{9}$ Seharusnya angka kejadian AV paling tinggi adalah pada laki-laki karena hormon androgen pada laki-laki memiliki peranan terhadap kelenjar sebasea yang sangat sensitif terhadap hormon ini, sehingga mengakibatkan kelenjar sebasea bertambah besar dan produksi sebum meningkat maka pada pria sering terjadi AV yang berat. $^{10}$ Tetapi pada perempuan kejadian AV dipengaruhi oleh hormononal, pada $60-70 \%$ wanita lesi AV menjadi lebih aktif kurang lebih satu minggu sebelum haid oleh karena hormon progesteron. Pemakaian kosmetik pada wanita dapat menyebabkan AV jika mengandung bahan-bahan yang komedogenik. ${ }^{5}$

Penelitian ini menunjukkan bahwa kelompok usia terbanyak yang menderita AV adalah usia 21 tahun 55 orang (84,6\%), lalu diikuti usia 22 tahun 10 orang $(15,4 \%)$. Hal ini tidak sesuai dengan penelitian yang dilakukan Sampelan, Pangamanan, and Kundre pada tahun 2017, berdasarkan umur didapatkan dalam penelitian ini yang terbanyak berusia $14-16$ tahun(88,1\%). ${ }^{5}$ Menurut Rahmawati (2012), insidensi tertinggi 
terdapat pada perempuan antara umur 14-17 tahun dan pada laki-laki antara umur 16-19 tahun. ${ }^{11}$ Pada waktu pubertas terdapat kenaikan dari hormon androgen yang beredar dalam darah yang dapat menyebabkan hyperplasia dan hipertrofi dari glandula sebasea sehingga tidak heran jika angka kejadian jerawat paling tinggi pada usia remaja. ${ }^{12}$

\begin{tabular}{ccc}
\multicolumn{2}{c}{ Berdasarkan hasil penelitian } \\
menurut Klasifikasi & Pillsburry
\end{tabular}
menunjukkan bahwa mahasiwa yang paling banyak menderita AV grade 1 berjumlah 37 orang $(56,9 \%)$, lalu diikuti AV grade 2 berjumlah 16 orang (24,6\%), AV grade 3 berjumlah 8 orang (12,3\%), AV grade 4 berjumlah 4 orang (6,2\%). Pada hasil penelitian, disimpulkan bahwa mahasiswa yang paling banyak mengalami AV grade 1. Hal ini sesuai dengan penelitian yang dilakukan oleh Sampelan, Pangamanan, and Kundre pada tahun 2017, yang menunjukkan bahwa jumlah responden yang mengalami AV ringan 26 responden (62,0\%), sedang 8 responden $(19,0)$, berat 8 responden $(19,0 \%)$. Dan sebagian besar terdapat pada AV ringan $(61,9 \%) .{ }^{5}$ Studi epidemiologi pada remaja yang mengalami AV di China menemukan bahwa faktor-faktor yang mempengaruhi AV pada remaja adalah riwayat keluarga, stres mental, gangguan menstruasi, insomnia, diet tinggi lemak, jenis kelamin laki-laki, dismenorea, ansietas, depresi, makanan yang digoreng, tekanan saat belajar, makanan pedas, kulit berminyak dan jenis kulit. Merokok dan konsumsi alkohol juga disebutkan sebagai faktor risiko. ${ }^{13}$

Berdasarkan hasil dari kuesioner HARS menunjukkan bahwa mahasiswa FK UMSU paling banyak mengalami gejala kecemasan yaitu kecemasan ringan yang berjumlah 19 orang $(29,2 \%)$, lalu diikuti kecemasan berat berjumlah 14 orang $(21,5 \%)$, kecemasan berat sekali berjumlah 12 orang (18,5\%), tidak ada kecemasan berjumlah 13 orang (20\%), dan kecemasan sedang berjumlah 7 orang $(10,8 \%)$. Pada hasil penelitian, disimpulkan bahwa mahasiswa paling banyak mengalami kecemasan ringan. Hal ini sesuai dengan penelitian yang dilakukan oleh Sampelan, Pangamanan, and Kundre pada tahun 2017, hasil penelitian yang di dapatkan bahwa jumlah tingkat kecemasan ringan (64,3\%), sedang (19,0\%), berat(16,7\%). Dan dari tingkat kecemasan sebagian besar terdapat pada ringan $(64,3 \%) .{ }^{5}$ Menurut Stuart (2006), kecemasan adalah suatu perasaan yang tidak pasti, tidak berdaya yang berkaitan dengan emosi seseorang terhadap suatu objek yang tidak spesifik. ${ }^{14}$ Pada mahasiswa FK UMSU yang paling banyak di temukan adalah kecemasan ringan, suatu kecemasan yang wajar terjadi pada individu akibat situasi-situasi yang mengancam dan individu tersebut tidak dapat mengatasinya, sehingga timbul kecemasan. ${ }^{15}$

Penelitian ini dilakukan untuk melihat adanya hubungan AV dengan gejala Ansietas dan didapatkan hasil yang menderita AV grade 1 mengalamai gejala kecemasan ringan 11 orang (16,9\%), tidak ada kecemasan 11 orang (16,9\%), kecemasan berat 8 orang $(12,3 \%)$, kecemasan sedang 5 orang $(7,7 \%)$, dan kecemasan berat sekali 2 orang $(3,1 \%)$, AV grade 2 mengalamai gejala kecemasan ringan 7 orang $(10,8 \%)$, kecemasan berat sekali 5 orang $(7,7 \%)$, kecemasan sedang 2 orang $(3,1 \%)$, dan kecemasan berat 2 orang $(3,1 \%)$, AV grade 3 mengalamai gejala kecemasan ringan 1 orang $(1,5 \%)$, tidak ada kecemasan 2 orang (3,1\%), kecemasan berat 3 orang $(4,6 \%)$, dan kecemasan berat sekali 2 orang $(3,1 \%)$, AV grade 4 mengalamai gejala kecemasan berat 1 orang $(1,5 \%)$, dan kecemasan berat sekali 3 orang $(4,6 \%)$. Pada uji chi-square di dapatkan hasil $p$-value 0,020 yang berarti terdapat hubungan acne vulgaris dengan 
gejala ansietas. Menurut Latifah (2016), bahwa prevalensi mahasiswa yang terdiagnosis menderita AV didapatkan adanya hubungan antara stress dengan kejadian AV. Hal ini disebabkan timbulnya AV berhubungan dengan kondisi kesehatan jiwa dan psikologis remaja salah satunya stress dan kecemasan. Antara psikis dan kondisi kulit saling mempengaruhi sebaliknya keadaan gangguan kulit dapat juga berpengaruh terhadap psikis. ${ }^{16}$ Menurut Andri, perilaku sosial, psikologis, dan emosional yang berasal dari AV telah dilaporkan mirip dengan perilaku yang terdapat pada epilepsi, asma, diabetes, dan artritis. ${ }^{17}$ Penatalaksanaan AV yang tidak optimal akan menimbulkan komplikasi yaitu timbulnya scar. Scar akan menyebabkan turunnya kepercayaan diri seseorang yang mengakibatkan meningkat nya gejala kecemasan. ${ }^{3}$ Keadaan kulit yang sehat sangatlah penting bagi kesehatan fisik dan mental seorangindividu. Keadaan ini terangkum dalam aspek penampilan rasa sehat dan bahagia serta rasa percaya diri. Hal itu disebabkan karena kulit merupakan organ terluas dan yang paling kelihatan dari tubuh manusia sehingga suatu penampilan kulit yang berbeda akan berpengaruh pada penampilan dan citra diri seseorang dan akan mempengaruhi orang itu sendiri. ${ }^{18,19}$

\section{KESIMPULAN}

Berdasarkan hasil penelitian dan pembahasan yang telah dijelaskan, maka dapat disimpulkan bahwa dari jenis kelamin yang paling banyak menderita AV adalah perempuan (58,5\%). Usia yang paling banyak menderita AV adalah 21 tahun (84,6\%). Didapatkan yang paling banyak menderita AV adalah AV grade 1 (56,9\%). Didapatkan yang paling banyak mengalami gejala kecemasan adalah kecemasan ringan (29,2\%). Terdapat hubungan AV dengan gejala kecemasan pada mahasiswa Fakultas Kedokteran Universitas Muhammadiyah Sumatera Utara.

\section{REFERENSI}

1. Adhi D, Aida SSD, Aryani S, et al. IImu Penyakit Kulit Dan Kelamin.; 2018.

2. Moradi Tuchayi S, Makrantonaki E, Ganceviciene R, Dessinioti C, Feldman $\mathrm{SR}$, Zouboulis CC. Acne vulgaris. Nat Rev Dis Prim. 2015. doi:10.1038/nrdp.2015.29

3. Husein-Elahmed $\mathrm{H}$. Management of acne vulgaris with hormonal therapies in adult female patients. Dermatol Ther. 2015. doi:10.1111/dth.12231

4. Duman H, Topal IO, Kocaturk E, Duman MA. Evaluation of anxiety, depression, and quality of life in patients with acne vulgaris, and quality of life in their families. Dermatologica Sin. 2016;34(1):6-9. doi:10.1016/j.dsi.2015.07.002

5. Sampelan MG, Pangamanan D, Kundre RM. Hubungan Timbulnya Acne Vulgaris Dengan Tingkat Kecemasan Pada Remaja di SMP N 1 Likupang Timur. e-Journal Keperawatan (e-Kp). 2017.

6. Gallitano SM, Berson DS. How Acne Bumps Cause the Blues: The Influence of Acne Vulgaris on Self-Esteem. Int $J$ Women's Dermatology. 2018;4(1):12-17. doi:10.1016/j.jijwd.2017.10.004

7. Locke AB, Kirst N, Shultz CG. Diagnosis and management of generalized anxiety disorder and panic disorder in adults. Am Fam Physician. 2015.

8. Katona, C., Cooper, C., Robertson, M., 2012. At a Glance Psikiatri edisi keempat. Jakarta : Erlangga.

9. Manarisip. C. M. Hubungan Stress dengan Kejadian Acne Vulgaris pada mahasiswa semester V Program Studi IImu Keperawatan Fakultas Kedokteran Universitas Sam Ratulangi manado. 2015

10. Harahap, M. 2000. Ilmu Penyakit Kulit. Edisi I. Jakarta:Hipokrates, pp 35-45.

11. Rahmawati, Dewi. Hubungan Perawatan Kulit Wajah Dengan Timbulnya Acne Vulgaris. Skripsi. FK UNDIP. Semarang. 2012

12. Yuindartanto, A,. Acne Vulgaris. Fakultas Kedokteran Universitas Indonesia. 2009

13. Suh DH et al. 'A multicenterepidemiological study of akne vulgaris in Korea.' Int $J$ Dermatol. 2011;50(6):673-681.

14. Stuart, Gail W. Buku Saku Keperawatan Kesehatan Jiwa. Jakarta: EGC. 2007 
15. Kartono, Kartini. Buku Teori Kepribadian. Bandung: CV mandar Maju. 2006

16. Latifah, S \& Kurniawaty, E.. Stres dengan Akne Vugaris. MahasiswaFakultas Kedokteran Universitas Lampung. Vol.4/No.9/ Desember 2015.

17. Andri, Kusumawardhani, Aryani,S. Perasaan SelfConsciousness danRendahnya Harga diri dan Hubungannya dengan Kualitas Hidup Pasien Akne Vulgaris. Maj Kedokt Indon. 60(6): 263-267. 2010.
18. Harnold. hubungan akne vulgaris dengan sindrom depresi. (2013) Di unduh dari https://www.scribd.com/doc/189204 146/Hubungan-Akne

Vulgaris Dengan-Sindrom-Depresi.

19. Tilla A; Hervina. Hubungan Tingkat Pengetahuan Dan Sikap Dengan Kejadian Acne Vulgaris Pada Remaja di SMA Muhammadiyah 02 Medan. Jurnal Pandu Husada, 2019, 1.1. 